\title{
IN VITRO ACTIVITY OF CALCIUM CHANNEL BLOCKERS IN COMBINATION WITH CONVENTIONAL ANTIFUNGAL AGENTS AGAINST CLINICALLY IMPORTANT FILAMENTOUS FUNGI
}

\author{
Mónika Homa, ${ }^{1,2}$ Kinga HegedŰs, ${ }^{2}$ ÁdÁm FÜLÖP, ${ }^{2}$ Vanessza Wolfárt, ${ }^{2}$ \\ Shine Kadaikunnan, ${ }^{3}$ Jamal M. Khaled, ${ }^{3}$ Naiyf S. Alharbi, ${ }^{3}$ \\ CSABA VÁGVÖLGYI ${ }^{2,3}$ and LÁsZló GALGÓCZY* \\ ${ }^{1}$ MTA-SZTE "Lendület” Fungal Pathogenicity Mechanisms Research Group, \\ Közép fasor 52, H-6726 Szeged, Hungary \\ ${ }^{2}$ Department of Microbiology, Faculty of Science and Informatics, University of Szeged, \\ Közép fasor 52, H-6726 Szeged, Hungary \\ ${ }^{3}$ Department of Botany and Microbiology, College of Science, King Saud University, \\ Riyadh 11451, Saudi Arabia
}

(Received: March 13, 2017; accepted: April 18, 2017)

\begin{abstract}
Despite the current therapeutic options, filamentous fungal infections are associated with high mortality rate especially in immunocompromised patients. In order to find a new potential therapeutic approach, the in vitro inhibitory effect of two antiarrhythmic agents, diltiazem and verapamil hydrochloride were tested against different clinical isolates of ascomycetous and mucoralean filamentous fungi. The in vitro combinations of these non-antifungal drugs with azole and polyene antifungal agents were also examined. Susceptibility tests were carried out using the broth microdilution method according to the instructions of the Clinical and Laboratory Standards Institute document M38-A2. Checkerboard microdilution assay was used to assess the interactions between antifungal and non-antifungal drugs. Compared to antifungal agents, diltiazem and verapamil hydrochloride exerted a relatively low antifungal activity with high minimal inhibitory concentration values $(853-2731 \mu \mathrm{g} / \mathrm{ml})$. Although in combination they could increase the antifungal activity of amphotericin B, itraconazole and voriconazole. Indifferent and synergistic interactions were registered in 33 and 17 cases, respectively. Antagonistic interactions were not revealed between the investigated compounds. However, the observed high MICs suggest that these agents could not be considered as alternative systemic antifungal agents.
\end{abstract}

Keywords: Diltiazem hydrochloride - verapamil hydrochloride - antifungal activity - drug combinations - synergistic interaction

\section{INTRODUCTION}

Filamentous fungi could be responsible for severe, opportunistic, life-threatening infections, especially among immunocompromised organ transplant and cancer patients [18]. Although the genus Aspergillus still remains the most common cause of invasive mould infections, non-Aspergillus moulds, such as Fusarium and Scedosporium species and members of the order Mucorales are also reported as emerging human pathogens in recent years $[6,19,26]$. Conventional antifungal drugs

\footnotetext{
*Corresponding author; e-mail address: galgoczi@gmail.com
} 


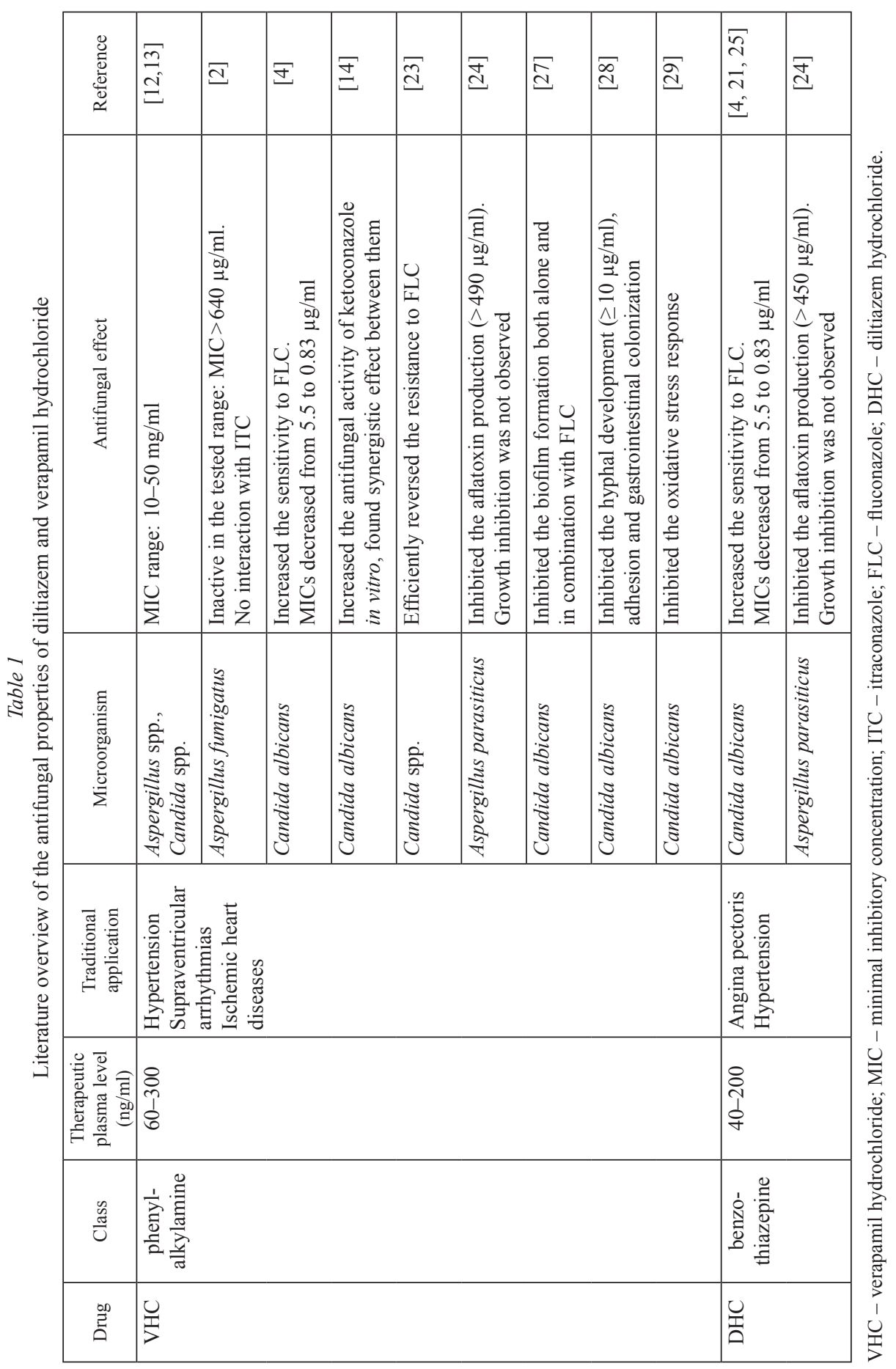

Acta Biologica Hungarica 68, 2017 
applied in clinical practice often have limited activity against these pathogens [7] Moreover, their long-term use may cause severe adverse effects in the patients. According to the recent studies, more than 1.6 million people die of a serious fungal infection each year despite the currently available antifungal treatments [9]. These facts underline the importance of developing novel, safely applicable antifungal therapeutic strategies.

Based on previous studies, several non-antifungal medications possess secondary antifungal activity in vitro. Calcium channel blockers (CCBs), which are commonly used as antiarrhythmic drugs, block the $\mathrm{Ca}^{2+}$ influx influencing the calmodulin system of the cell, which modulates metabolism and growth [1]. Verapamil hydrochloride (VHC) is a phenylalkylamine CCB, exerts inhibitory effect on Candida and Aspergillus species (Table 1) $[2,28,29]$. Diltiazem hydrochloride (DHC) belongs to the benzothiazepine class of CCBs and it is able to increase the sensitivity of Candida albicans to fluconazole (FLC) (Table 1) [4]. These non-antifungal drugs, as monotherapeutic agents or in combination with conventional antifungals could serve as a potential basis for a novel therapeutic approach.

Considering the above-mentioned arguments, the objectives of the present work were (i) to examine and compare the in vitro antifungal effect of two CCBs (i.e., DHC and $\mathrm{VHC}$ ) and conventional antifungal drugs (i.e., amphotericin B, AmB; FLC; itraconzole, ITC; ketoconazole, KTC; terbinafine, TRB; and voriconazole, VRC), and (ii) to investigate their in vitro combinations against clinical isolates of ascomycetous and mucoralean fungi.

\section{MATERIALS AND METHODS}

\section{Strains}

Ten ascomycetous and mucoralean fungal strains from different human infections were involved in the present study: Aspergillus fumigatus (Szeged Microbiology Collection, Szeged, Hungary; SZMC 2394 from keratitis), a member of the Fusarium solani species complex (SZMC 11412 from keratitis), Scedosporium aurantiacum (Centraalbureau voor Schimmelcultures, Utrecht, The Netherlands; CBS 136046 from lung infection), Scedosporium boydii (CBS 120157 from lung infection), Trichoderma longibrachiatum (Devonian Botanic Garden, University of Alberta Herbarium and Microfungus Collection, Edmonton, Alberta, Canada; UAMH 7955 from sinus infection), Lichtheimia corymbifera (SZMC 95033 from lung infection), Rhizopus microsporus var. rhizopodiformis (CBS 102277 from rhinocerebral infection), Rhizomucor miehei (CBS 360.92 from kidney and liver infection), Rhizopus oryzae (CBS 146.90 from soft palate infection), and Rhizomucor pusillus (Swiss Federal Institute of Technology Culture Collection, Zurich, Switzerland; ETH M4920 from tracheal discharge). All the isolates were maintained on malt extract agar (MEA, Biolab) slants. 


\section{Susceptibility testing}

The in vitro minimal inhibitory concentration (MIC) values were determined using the broth microdilution method following the guidelines described in the CLSI M38A2 document [5].

The antifungal effect of two CCBs (i.e., DHC and VHC [Sigma-Aldrich]) and seven clinically used antifungal agents (i.e., AmB [Medispec Pharmaceuticals Pvt. Ltd], FLC [Molekula Ltd.], CLT, ITC, KTC, TRB [Sigma-Aldrich], and VRC [Pfizer Inc.]) was investigated and compared. Stock solutions of non-antifungal agents were prepared in sterile distilled water, while antifungal agents were dissolved in the solvents recommended by CLSI M38-A2 document [5]. Further dilutions were prepared in the testing medium, RPMI-1640 buffered to $\mathrm{pH} 7.0$ with $0.165 \mathrm{~mol} / \mathrm{l}$ 3 -[N-morpholino] propanesulfonic acid (Sigma-Aldrich). The final concentration ranges were $128-4096 \mu \mathrm{g} / \mathrm{ml}$ for CCBs and $0.25-128 \mu \mathrm{g} / \mathrm{ml}$ for antifungal drugs. Considering the speeds of germination and growth, microtiter plates of mucoralean fungi were evaluated after 24 hours, whilst Aspergillus, Fusarium and Trichoderma strains after 48 hours, and Scedosporium strains after 72 hours of incubation at $37^{\circ} \mathrm{C}$. Results were read using a microplate reader in well-scanning mode (SPECTROstar Nano, Germany). Untreated control samples served as growth controls and we take their absorbance $\left(\mathrm{OD}_{620}\right)$ as $100 \%$. MIC was defined as the lowest concentration of the tested compound that totally inhibited the growth of the fungus on the basis of the $\mathrm{OD}_{620}$ values as compared to the untreated control.

\section{Combination tests}

Interactions were investigated between $\mathrm{CCBs}$ and $\mathrm{AmB}$, ITC, and VRC using the checkerboard microdilution method [8]. Interactions between VHC and $\mathrm{AmB}$ were not tested, since according to the drug information leaflet provided by the manufacturer, the co-administration of these two drugs should be avoided. The final concentration ranges of each drug were chosen based on the MIC data obtained by the antifungal susceptibility tests. Fractional inhibitory concentration index (FICI) values were calculated to describe the interactions between the compounds as described previously [11]. Synergism was defined as $\mathrm{FICI} \leq 0.5$, indifference as $0.5<\mathrm{FICI} \leq 4$, and antagonism was defined when FICI was $>4$ [22].

\section{RESULTS}

\section{Susceptibility testing}

Results of the susceptibility tests are presented in Table 2. In general, the MICs of DHC and VHC were quite high, but mucoralean isolates (MIC range: 853-2048 $\mu \mathrm{g} /$ $\mathrm{ml}$ ) proved to be slightly more susceptible to these non-antifungal drugs than the 


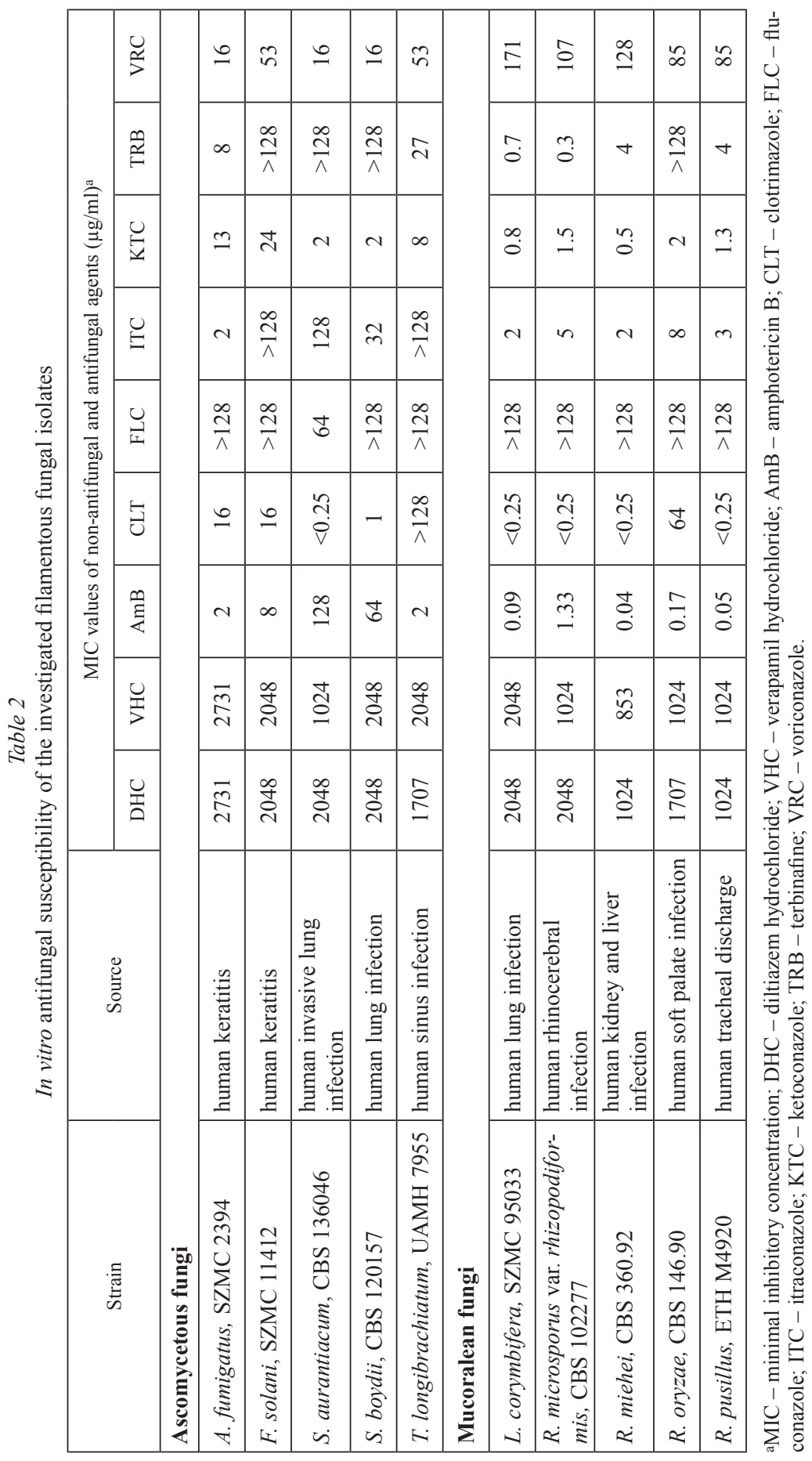


ascomycetous isolates (MIC range: $1024-2731 \mu \mathrm{g} / \mathrm{ml}$ ). Differences in the susceptibility to antifungal drugs were also observed between the two groups: while VRC was more effective against ascomycetous fungi, mucoralean fungi proved to be more susceptible to AmB, ITC and KTC. Against the investigated Ascomycetes, KTC proved to be the most effective antifungal drug (MIC range: $2-24 \mu \mathrm{g} / \mathrm{ml}$ ), followed by VRC (MIC range: $16-53 \mu \mathrm{g} / \mathrm{ml}$ ). MICs of ITC were generally high, but $A$. fumigatus SZMC 2394 (MIC: $2 \mu \mathrm{g} / \mathrm{ml}$ ) was susceptible to it. AmB and KTC proved to be the most effective antifungals against mucoralean isolates with MICs ranging between $0.04-1.33 \mu \mathrm{g} / \mathrm{ml}$ and $0.5-2 \mu \mathrm{g} / \mathrm{ml}$, respectively. The growth of mucoralean fungi was also inhibited by low concentrations of CLT (MICs $<0.25 \mu \mathrm{g} / \mathrm{ml}$ ) and TRB (MIC range: $0.3-4 \mu \mathrm{g} / \mathrm{ml}$ ), except the case of $R$. oryzae CBS 146.90, where the MICs of $64 \mu \mathrm{g} / \mathrm{ml}$ for CLT and $>28 \mu \mathrm{g} / \mathrm{ml}$ for TRB were recorded. With one exception (S. aurantiacum CBS 136046, MIC: $64 \mu \mathrm{g} / \mathrm{ml}$ ), FLC was ineffective against all isolates in the investigated concentration range. Summarizing, conventional antifungal drugs proved to be more effective than CCBs.

\section{Combination tests}

The results of the combination tests are summarized in Tables 3 and 4. Compared to the single use, the relatively high MIC values $(853-2731 \mu \mathrm{g} / \mathrm{ml})$ of CCBs decreased or remained the same in the combination tests (MIC range: 32-> $2048 \mu \mathrm{g} / \mathrm{ml}$ ). Antagonistic interactions were not detected between the investigated compounds. Synergistic and indifferent interactions were revealed in 17 and 33 cases, respectively. Between VHC and VRC, and DHC and VRC only indifferent interactions were observed; while the interactions of CCBs with ITC were synergistic in most cases. Between AmB and DHC no interactions were revealed against all mucoralean isolates, while against ascomycetous fungi synergistic and indifferent interactions were registered in three and two cases, respectively.

\section{DISCUSSION}

The antifungal effect of CCBs has been investigated previously against Candida and Aspergillus species, but data on its effect against other human pathogenic ascomycetous and mucoralean fungi are not reported in the literature (Table 1). Basically, our results are in agreement with these reports: relative high concentrations of DHC and VHC inhibited the growth of the investigated fungal strains, MICs were between 853 and $2731 \mu \mathrm{g} / \mathrm{ml}$ (Table 2). These values are much higher than their therapeutically available plasma levels (Table 1). Khalaf et al. [12] observed a much broader and higher MIC range $(10,000-50,000 \mu \mathrm{g} / \mathrm{ml})$ for Aspergillus and Candida strains. Afeltra et al. [2] reported that VHC was inactive against Aspergillus fumigatus (MIC $>640 \mu \mathrm{g} / \mathrm{ml}$ ). In another study, Aspergillus parasiticus also proved to be resistant to VHC and DHC, but their applied concentrations $(<490 \mu \mathrm{g} / \mathrm{ml}$ and $<450 \mu \mathrm{g} / \mathrm{ml}$, 
Table 3

In vitro antifungal activity of diltiazem hydrochloride in combination with conventional antifungal agents against ascomycetous and mucoralean fungal strains

\begin{tabular}{|c|c|c|c|c|c|c|}
\hline \multirow{2}{*}{ Isolate } & \multicolumn{4}{|c|}{ Antifungal agent/MIC values $(\mu \mathrm{g} / \mathrm{ml})^{\mathrm{a}}$} & \multirow{2}{*}{$\mathrm{FICI}^{\mathrm{b}}$} & \multirow{2}{*}{ Interaction $^{\mathrm{c}}$} \\
\hline & $\mathrm{DHC}_{\text {alone }}$ & $\mathrm{DHC}_{\text {in combination }}$ & $\mathrm{AmB}_{\text {alone }}$ & $\mathrm{AmB}_{\text {in combination }}$ & & \\
\hline \multicolumn{7}{|l|}{ Ascomycetous fungi } \\
\hline A. fumigatus & 2731 & 2048 & 2 & 2 & 1.75 & NI \\
\hline F. solani & 2048 & 256 & 8 & 2 & 0.38 & S \\
\hline \multirow[t]{2}{*}{ S. aurantiacum } & 2048 & 512 & 128 & 16 & 0.38 & $\mathrm{~S}$ \\
\hline & 2048 & 256 & 128 & 32 & 0.38 & S \\
\hline S. boydii & 2048 & 32 & 64 & 8 & 0.14 & $\mathrm{~S}$ \\
\hline T. longibrachiatum & 1707 & 1024 & 2 & 0.5 & 0.85 & NI \\
\hline \multicolumn{7}{|l|}{ Mucoralean fungi } \\
\hline L. corymbifera & 2048 & 2048 & 0.09 & 0.015 & 1.17 & NI \\
\hline R. microsporus & 2048 & 1024 & 1.3 & 0.25 & 0.69 & NI \\
\hline R. miehei & 1024 & 128 & 0.04 & 0.06 & 1.63 & NI \\
\hline R. oryzae & 1707 & 256 & 0.17 & 0.25 & 1.62 & NI \\
\hline R. pusillus & 1024 & 2048 & 0.05 & 0.001 & 2.02 & NI \\
\hline
\end{tabular}

\begin{tabular}{|c|c|c|c|c|c|c|}
\hline \multirow{2}{*}{ Isolate } & \multicolumn{4}{|c|}{ Antifungal agent/MIC values $(\mu \mathrm{g} / \mathrm{ml})^{\mathrm{a}}$} & \multirow{2}{*}{$\mathrm{FICI}^{\mathrm{b}}$} & \multirow{2}{*}{ Interaction $^{\mathrm{c}}$} \\
\hline & $\mathrm{DHC}_{\text {alone }}$ & $\mathrm{DHC}_{\text {in combination }}$ & $\mathrm{VRC}_{\text {alone }}$ & $\mathrm{VRC}_{\text {in combination }}$ & & \\
\hline \multicolumn{7}{|l|}{ Ascomycetous fungi } \\
\hline A. fumigatus & 2731 & 2048 & 16 & 4 & 1.00 & NI \\
\hline F. solani & 2048 & 2048 & 53 & 4 & 1.08 & NI \\
\hline \multirow[t]{2}{*}{ S. aurantiacum } & 2048 & 2048 & 16 & 1 & 1.06 & NI \\
\hline & 2048 & 128 & 16 & 16 & 1.06 & NI \\
\hline S. boydii & 2048 & 128 & 16 & 8 & 0.56 & NI \\
\hline T. longibrachiatum & 1707 & 128 & 53 & 32 & 0.68 & NI \\
\hline \multicolumn{7}{|l|}{ Mucoralean fungi } \\
\hline L. corymbifera & 2048 & 2048 & 171 & 256 & 2.50 & NI \\
\hline R. microsporus & 2048 & 2048 & 107 & 8 & 1.07 & NI \\
\hline R. miehei & 1024 & 1024 & 128 & 8 & 1.06 & NI \\
\hline R. oryzae & 1707 & 2048 & 85 & 8 & 1.29 & NI \\
\hline R. pusillus & 1024 & 2048 & 85 & 8 & 2.09 & NI \\
\hline
\end{tabular}


Table 3 (cont.)

\begin{tabular}{|c|c|c|c|c|c|c|}
\hline \multirow{2}{*}{ Isolate } & \multicolumn{4}{|c|}{ Antifungal agent/MIC values $(\mu \mathrm{g} / \mathrm{ml})^{\mathrm{a}}$} & \multirow{2}{*}{$\mathrm{FICI}^{\mathrm{b}}$} & \multirow{2}{*}{ Interaction ${ }^{\mathrm{c}}$} \\
\hline & $\mathrm{DHC}_{\text {alone }}$ & $\mathrm{DHC}_{\text {in combination }}$ & $\mathrm{ITC}_{\text {alone }}$ & $\mathrm{ITC}_{\text {in combination }}$ & & \\
\hline \multicolumn{7}{|l|}{ Ascomycetous fungi } \\
\hline A. fumigatus & 2731 & 128 & 2 & 0.5 & 0.30 & S \\
\hline F. solani & 2048 & $>2048$ & $>128$ & $>128$ & $>0.50$ & NI \\
\hline S. aurantiacum & 2048 & 128 & 128 & 8 & 0.13 & $\mathrm{~S}$ \\
\hline S. boydii & 2048 & 128 & 32 & 2 & 0.13 & $\mathrm{~S}$ \\
\hline T. longibrachiatum & 1707 & 1024 & $>128$ & 1 & $>0.50$ & NI \\
\hline \multicolumn{7}{|l|}{ Mucoralean fungi } \\
\hline L. corymbifera & 2048 & 128 & 2 & 0.25 & 0.19 & $\mathrm{~S}$ \\
\hline R. microsporus & 2048 & 2048 & 5 & 0.03 & 1.01 & NI \\
\hline R. miehei & 1024 & 128 & 2 & 0.5 & 0.38 & $\mathrm{~S}$ \\
\hline$R$. oryzae & 1707 & 128 & 8 & 1 & 0.20 & $\mathrm{~S}$ \\
\hline R. pusillus & 1024 & 128 & 3 & 0.25 & 0.21 & $\mathrm{~S}$ \\
\hline
\end{tabular}

${ }^{\mathrm{a}} \mathrm{MIC}$ - minimum inhibitory concentration; $\mathrm{DHC}_{\text {alone, }} \mathrm{AmB}_{\text {alone }}, \mathrm{ITC}_{\text {alone }}$ and $\mathrm{VRC}_{\mathrm{alone}}-$ mean $\mathrm{MICs}$ of diltiazem hydrochloride, amphotericin $\mathrm{B}$, itraconazole, and voriconazole, respectively, when applied alone; $\mathrm{DHC}_{\text {in combination, }}, \mathrm{AmB}_{\text {in combination, }} \mathrm{ITC}_{\text {in combination, }}$ and $\mathrm{VRC}_{\text {in combination, }}$, mean MICs of diltiazem hydrochloride, amphotericin B, itraconazole, and voriconazole, respectively, when applied in combination.

bFICI - fractional inhibitory concentration index.

c S - synergism $(\mathrm{FICI} \leq 0.5)$; NI - no interaction $(0.5<\mathrm{FICI} \leq 4)[22]$.

respectively) could inhibit the aflatoxin production of this strain [24]. VHC inhibited the adhesion, gastrointestinal colonization and the oxidative stress response of C. albicans and significantly decreased the hyphal development in a concentration of $\geq 10 \mu \mathrm{g} / \mathrm{ml}[28,29]$.

Our findings on the interactions between $\mathrm{CCBs}$ and conventional antifungal drugs are comparable to previously reported observations. We proved that DHC and VHC could interact synergistically with azoles and polyene antifungals (Tables 3,4). While in these tests the MICs of non-antifungal drugs were still beyond their in vivo achievable plasma concentrations, the MICs of AmB, ITC and VRC could be decreased to their therapeutic plasma levels $[3,10,16]$.

Krajewska-Kułak and Niczyporuk [14] reported that VHC and other CCBs increased the antifungal activity of ketoconazole against $C$. albicans strains in vitro and found synergistic effect between them. Afeltra et al. [2] observed no interaction between VHC and ITC against $A$. fumigatus. The sensitivity of $C$. albicans to FLC was increased dramatically in the presence of DHC and VHC [4]. Other calcium channel antagonists were tested by Liu et al. [17] against FLC-resistant Candida strains. All the CCBs exhibited no antifungal activity with MICs $>512 \mu \mathrm{g} / \mathrm{ml}$, 
Table 4

In vitro antifungal activity of verapamil hydrochloride in combination with conventional antifungal agents against ascomycetous and mucoralean fungal strains

\begin{tabular}{|c|c|c|c|c|c|c|}
\hline \multirow{2}{*}{ Isolate } & \multicolumn{4}{|c|}{ Antifungal agent/MIC values $(\mu \mathrm{g} / \mathrm{ml})^{\mathrm{a}}$} & \multirow{2}{*}{$\mathrm{FICI}^{\mathrm{b}}$} & \multirow{2}{*}{ Interaction $^{\mathrm{c}}$} \\
\hline & $\mathrm{VHC}_{\text {alone }}$ & $\mathrm{VHC}_{\text {in combination }}$ & $\mathrm{VRC}_{\text {alone }}$ & $\mathrm{VRC}_{\text {in combination }}$ & & \\
\hline \multicolumn{7}{|l|}{ Ascomycetous fungi } \\
\hline A. fumigatus & 2731 & 2048 & 16 & 4 & 1.00 & NI \\
\hline F. solani & 2048 & 2048 & 53 & 4 & 1.08 & NI \\
\hline S. aurantiacum & 1024 & 128 & 16 & 8 & 0.63 & NI \\
\hline S. boydii & 2048 & 128 & 16 & 8 & 0.56 & NI \\
\hline T. longibrachiatum & 2048 & 128 & 53 & 32 & 0.67 & NI \\
\hline \multicolumn{7}{|l|}{ Mucoralean fungi } \\
\hline L. corymbifera & 2048 & 2048 & 171 & 8 & 1.05 & NI \\
\hline R. microsporus & 1024 & 1024 & 107 & 8 & 1.07 & NI \\
\hline R. miehei & 853 & 256 & 128 & 64 & 0.80 & NI \\
\hline R. oryzae & 1024 & 1024 & 85 & 8 & 1.09 & NI \\
\hline R. pusillus & 1024 & 1024 & 85 & 8 & 1.09 & NI \\
\hline \multirow{2}{*}{ Isolate } & \multicolumn{4}{|c|}{ Antifungal agent/MIC values $(\mu \mathrm{g} / \mathrm{ml})^{\mathrm{a}}$} & \multirow{2}{*}{$\mathrm{FICI}^{\mathrm{b}}$} & \multirow{2}{*}{ Interaction ${ }^{\mathrm{c}}$} \\
\hline & $\mathrm{VHC}_{\text {alone }}$ & $\mathrm{VHC}_{\text {in combination }}$ & $\mathrm{ITC}_{\text {alone }}$ & $\mathrm{ITC}_{\text {alone }}$ & & \\
\hline \multicolumn{7}{|l|}{ Ascomycetous fungi } \\
\hline A. fumigatus & 2731 & 128 & 2 & 0.5 & 0.30 & $\mathrm{~S}$ \\
\hline F. solani & 2048 & 2048 & $>128$ & $>128$ & 2.00 & NI \\
\hline S. aurantiacum & 2048 & 256 & 128 & 16 & 0.25 & $\mathrm{~S}$ \\
\hline S. boydii & 2048 & 128 & 32 & 2 & 0.13 & $\mathrm{~S}$ \\
\hline T. longibrachiatum & 2048 & 1024 & $>128$ & 4 & $>0.50$ & NI \\
\hline \multicolumn{7}{|l|}{ Mucoralean fungi } \\
\hline L. corymbifera & 2048 & 128 & 2 & 0.125 & 0.13 & $\mathrm{~S}$ \\
\hline R. microsporus & 1024 & 128 & 5 & 1 & 0.33 & $\mathrm{~S}$ \\
\hline R. miehei & 853 & 64 & 2 & 0.25 & 0.20 & $\mathrm{~S}$ \\
\hline R. oryzae & 2048 & 1024 & 8 & 0.25 & 0.53 & NI \\
\hline R. pusillus & 1024 & 64 & 3 & 0.125 & 0.10 & $\mathrm{~S}$ \\
\hline
\end{tabular}

${ }^{\mathrm{a}} \mathrm{MIC}$ - minimum inhibitory concentration; $\mathrm{VHC}_{\mathrm{alone}}, \mathrm{AmB}_{\mathrm{alone}}, \mathrm{ITC}_{\text {alone, }}$ and $\mathrm{VRC}_{\mathrm{alone}}-$ mean $\mathrm{MICs}$ of verapamil hydrochloride, amphotericin $\mathrm{B}$, itraconazole, and voriconazole, respectively, when applied alone; $\mathrm{VHC}_{\text {in combination }}, \mathrm{AmB}_{\text {in combination }}, \mathrm{ITC}_{\text {in combination, }}$ and $\mathrm{VRC}_{\text {in combination, }}$, mean MICs of verapamil hydrochloride, amphotericin B, itraconazole, and voriconazole, respectively, when applied in combination.

bFICI - fractional inhibitory concentration index.

c $\mathrm{S}-$ synergism $(\mathrm{FICI} \leq 0.5)$; $\mathrm{NI}-$ no interaction $(0.5<\mathrm{FICI} \leq 4)[22]$. 
although, in combination with FLC, strong synergistic interactions were revealed. Moreover, Pina-Vaz et al. [23] observed that FLC resistance of Candida strains could be efficiently reverted by the application of VHC.

As CCBs affect all eukaryotic cells, their potential clinical use as antifungal agents must be clarified by further studies. The influence of DHC and VHC on human peritoneal polymorphonuclear cells and monocytes were investigated by Levy et al. [15]. The authors reported that these CCBs significantly reduced the bactericidal and fungicidal activity of phagocytic cells in vitro, however in vivo this effect was not observed. In addition to this, CCBs are both substrates and inhibitors of the cytochrome P450 family CYP3A4. Their co-administration with other drugs that share the CYP3A4 pathway (e.g. azoles) may alter the pharmacokinetic properties and increase the plasma levels of both drugs [20]. Optimal therapeutic drug-level monitoring and dosage adjustments may also be necessary during therapy to avoid serious side effects.

In conclusion, the in vitro sensitivity of both ascomycetous and mucoralean fungi to azoles and AmB could be increased with the addition of DHC and VHC in the testing media. However, their observed high MIC values and low therapeutic plasma level suggest that these agents could not be administered systemically. A possible limitation of our study is that one isolate per species was investigated only, however antifungal susceptibility might vary among different isolates of the same species.

\section{ACKNOWLEDGEMENTS}

L.G. is supported by the Postdoctoral Excellence Programme (PD 120808) of the Hungarian National Research, Development and Innovation Office (NKFI Office). The authors extend their sincere appreciation to the Deanship of Scientific Research at King Saud University for the support in the frame of the International Scientific Partnership Program (ISPP). This work was also connected to the project GINOP2.3.2-15-2016-00012.

\section{REFERENCES}

1. Afeltra, J., Verweij, P. E. (2003) Antifungal activity of non-antifungal drugs. Eur. J. Clin. Microbiol. Infect. Dis. 22, 397-407.

2. Afeltra, J., Vitale, R. G., Mouton, J. W., Verweij, P. E. (2004) Potent synergistic in vitro interaction between nonantimicrobial membrane-active compounds and itraconazole against clinical isolates of Aspergillus fumigatus resistant to itraconazole. Antimicrob. Agents Chemother. 48, 1335-1343.

3. Ashbee, H. R., Barnes, R. A., Johnson, E. M., Richardson, M. D., Gorton, R., Hope, W. W. (2014) Therapeutic drug monitoring (TDM) of antifungal agents: guidelines from the British Society for Medical Mycology. J. Antimicrob. Chemother. 69, 1162-1176.

4. Bulatova, N. R., Darwish, R. M. (2008) Effect of chemosensitizers on minimum inhibitory concentrations of fluconazole in Candida albicans. Med. Princ. Pract. 17, 117-121.

5. CLSI (2008) Reference method for broth dilution antifungal susceptibility testing of filamentous fungi; Approved Standard - Second Edition. CLSI document M38-A2. Clinical and Laboratory Standards Institute, Wayne.

6. Crabol, Y., Lortholary, O. (2014) Invasive mold infections in solid organ transplant recipients. Scientifica 2014, 821969 . 
7. Denning, D. W., Bromley, M. J. (2015) How to bolster the antifungal pipeline. Science 347, 14141416.

8. Eliopoulos, G. M., Moellering, R. C. (1996) Antimicrobial combinations. In: Lorian, V. (ed.) Antibiotics In Laboratory Medicine. $4^{\text {th }}$ Edition. The Williams and Wilkins Co., Baltimore, pp. 330-396.

9. GAFFI - Global Action Fund for Fungal Infections (2015) Report on activities for 2015. Available from: http://www.gaffi.org/official-documents-and-reports/. Accessed 21 July 2016.

10. Hamill, R. J. (2013) Amphotericin B formulations: a comparative review of efficacy and toxicity. Drugs 73, 919-934.

11. Johnson, M. D., MacDougall, C., Ostrosky-Zeichner, L., Perfect, J. R., Rex, J. H. (2004) Combination antifungal therapy. Antimicrob. Agents Chemother. 48, 693-715.

12. Khalaf, R. M., Jabir, H. B., Abbas, F. N. (2012) Investigation of the antifungal activity of some nonantifungal drugs in clinical isolates of otomycosis. J. Thi-Qar. Sci. 3, 31-39.

13. Köppel, C., Wagemann, A. (1991) Plasma level monitoring of D,L-verapamil and three of its metabolites by reversed-phase high-performance liquid chromatography. J. Chromatogr. 570, 229-234.

14. Krajewska-Kułak, E., Niczyporuk, W. (1993) Effects of the combination of ketoconazole and calcium channel antagonists against Candida albicans in vitro. Arzneimittelforschung 43, 782-783.

15. Levy, R., Dana, R., Gold, B., Alkan, M., Schlaeffer, F. (1991) Influence of calcium channel blockers on polymorphonuclear and monocyte bactericidal and fungicidal activity. Isr. J. Med. Sci. 27, 301-306.

16. Lewis, R. E. (2008) What is the "therapeutic range" for voriconazole? Clin. Infect. Dis. 46, 212-214.

17. Liu, S., Yue, L., Gu, W., Li, X., Zhang, L., Sun, S. (2016) Synergistic effect of fluconazole and calcium channel blockers against resistant Candida albicans. PLoS ONE 11, e0150859.

18. Low, C.-Y., Rotstein, C. (2011) Emerging fungal infections in immunocompromised patients. F1000 Med. Rep. 3, 14.

19. Mendoza, L., Vilela, R., Voelz, K., Ibrahim, A. S., Voigt, K., Lee, S. C. (2014) Human fungal pathogens of Mucorales and Entomophthorales. Cold Spring Harb. Perspect. Med. 5, a019562.

20. Methaneethorn, J., Chamnansua, M., Kaewdang, N., Lohitnavy, M. (2014) A pharmacokinetic drugdrug interaction model of simvastatin and verapamil in humans. Conf. Proc. IEEE Eng. Med. Biol. Soc. 2014, 5711-5714.

21. Monteiro, N., Silvestre, J., Gonçalves-Pereira, J., Tapadinhas, C., Mendes, V., Póvoa, P. (2013) Severe diltiazem poisoning treated with hyperinsulinaemia-euglycaemia and lipid emulsion. Case Rep. Crit. Care 2013, 138959.

22. Odds, F. C. (2003) Synergy, antagonism, and what the chequerboard puts between them. J. Antimicrob. Chemother. 52, 1.

23. Pina-Vaz, C., Rodrigues, A. G., Costa-de-Oliveira, S., Ricardo, E., Mårdh, P. A. (2005) Potent synergic effect between ibuprofen and azoles on Candida resulting from blockade of efflux pumps as determined by FUN-1 staining and flow cytometry. J. Antimicrob. Chemother. 56, 678-685.

24. Praveen, R. J., Subramanyam, C. (1999) Requirement of $\mathrm{Ca}^{2+}$ for aflatoxin production: inhibitory effect of $\mathrm{Ca}^{2+}$ channel blockers on aflatoxin production by Aspergillus parasiticus NRRL 2999. Lett. Appl. Microbiol. 28, 85-88.

25. Richards, D., Aronson, J., Reynolds, D. J., Coleman, J. (2011) Oxford Handbook of Practical Drug Therapy. $2^{\text {nd }}$ Edition. Oxford University Press, Oxford.

26. Roilides, E., Dotis, J., Katragkou, A. (2007) Fusarium and Scedosporium: emerging fungal pathogens. In: Kavanagh, K. (ed.) New Insights in Medical Mycology. Springer, Dordrecht, pp. 267-285.

27. Yu, Q., Ding, X., Xu, N., Cheng, X., Qian, K., Zhang, B., Xing, L., Li, M. (2013) In vitro activity of verapamil alone and in combination with fluconazole or tunicamycin against Candida albicans biofilms. Int. J. Antimicrob. Agents 41, 179-182.

28. Yu, Q., Ding, X., Zhang, B., Xu, N., Jia, C., Mao, J., Zhang, B., Xing, L., Li, M. (2014) Inhibitory effect of verapamil on Candida albicans hyphal development, adhesion and gastrointestinal colonization. FEMS Yeast Res. 14, 633-641.

29. Yu, Q., Xiao, C., Zhang, K., Jia, C., Ding, X., Zhang, B., Wang, Y., Li, M. (2014) The calcium channel blocker verapamil inhibits oxidative stress response in Candida albicans. Mycopathologia 177, $167-177$. 